\title{
The interaction between arterial oxygenation and carbon dioxide and hospital mortality following out of hospital cardiac arrest: a cohort study-do not dismiss confounders!
}

\author{
Romain Jouffroy and Benoît Vivien ${ }^{*}$
}

To the Editor,

In a recent study, McGuigan et al. [1] reported that a low $\mathrm{PaO} 2 / \mathrm{FiO} 2$ ratio, hypoxemia, and hypocapnia are associated with higher mortality following out of hospital cardiac arrest (OHCA) and secondly that $\mathrm{PaCO} 2$ modifies the relationship between oxygenation and mortality following OHCA.

Whereas the authors should be congratulated for their noteworthy study, we believe that their interpretation requires some cautions.

First, McGuigan et al. choose a $\mathrm{PaO} 2>100 \mathrm{mmHg}$ to define hyperoxemia and a $\mathrm{PaO} 2$ of $150-200 \mathrm{mmHg}$ as reference category. Conversely, in the two first princeps papers reporting an association between arterial hyperoxia following resuscitation from cardiac arrest and in-hospital mortality, Kilgannon et al. [2] and Bellomo et al. [3] have defined hyperoxia as a $\mathrm{PaO} 2>300 \mathrm{mmHg}$. Consequently, the large interval of $\mathrm{PaO} 2$ considered by McGuigan et al. [1] does not guarantee that mortality is uniform for all the patients presenting with a $\mathrm{PaO} 2>100 \mathrm{mmHg}$, and could fully explain the discrepancy with the results of Kilgannon et al. [2] and Bellomo et al. [3].

Secondly, the interpretation of $\mathrm{PaO} 2$ and $\mathrm{PaCO} 2$ values would have been more pertinent if the authors

This comment refers to the article available at https://doi.org/10.1186/ s13054-020-03039-6.

* Correspondence: benoit.vivien@aphp.fr

SAMU de Paris, Service d'Anesthésie Réanimation, Hôpital Universitaire Necker - Enfants Malades, Assistance Publique - Hôpitaux de Paris, APHP. Centre and Université de Paris, Paris, France had presented the time and cause of death of the patients. On the one hand, hypoxemic patients $(\mathrm{PaO} 2<$ $60 \mathrm{mmHg}$ ) were probably those suffering from respiratory injuries following cardiac arrest, i.e., mainly aspiration and/or alveolar hemorrhage. While it could be hypothesized that a protective ventilation strategy had been initiated for them, inducing high $\mathrm{PaCO} 2$ values, the direct effect of $\mathrm{PaCO} 2$ by itself is limited on respiratory function and therefore on mortality from respiratory origin [4]. On the other hand, for patients presenting with neurological injury but without respiratory insufficiency, the effect of $\mathrm{PaCO} 2$ should be considered as ambivalent. In the absence of cerebral edema, hypocapnia is deleterious by reducing cerebral blood flow and exacerbating cerebral ischemia; on the opposite, for patients presenting with cerebral edema following cardiac arrest resuscitation, hypercapnia is deleterious by inducing cerebral vasodilation. Nevertheless, the cause of death for patients with neurological assault following cardiac arrest, whatever they were hypocapnic or hypercapnic, was probably mainly from neurological origin.

Finally, the post cardiac arrest resuscitation period must be considered as a bundle of care, in which the therapeutic strategy should be multimodal and mostly individualized for each patient [5].

C C The Author(s). 2020 Open Access This article is licensed under a Creative Commons Attribution 4.0 International License, which permits use, sharing, adaptation, distribution and reproduction in any medium or format, as long as you give appropriate credit to the original author(s) and the source, provide a link to the Creative Commons licence, and indicate if changes were made. The images or other third party material in this article are included in the article's Creative Commons licence, unless indicated otherwise in a credit line to the material. If material is not included in the article's Creative Commons licence and your intended use is not permitted by statutory regulation or exceeds the permitted use, you will need to obtain permission directly from the copyright holder. To view a copy of this licence, visit http://creativecommons.org/licenses/by/4.0/ The Creative Commons Public Domain Dedication waiver (http://creativecommons.org/publicdomain/zero/1.0/) applies to the data made available in this article, unless otherwise stated in a credit line to the data. 


\section{Authors' response}

\section{Peter J. McGuigan, Manu Shankar-Hari, David A. Harrison, John G. Laffey and Danny F. McAuley}

Dear Editor,

We thank Dr. Jouffroy and Professor Vivien for their interest in our study. We would point out that the reference category in our study was hyperoxia (defined as a $\mathrm{PaO} 2>100 \mathrm{mmHg}$ ). We apologize if this was not clear in the original text.

Firstly, the authors argue that our choice of a $\mathrm{PaO} 2>100 \mathrm{mmHg}$ as a threshold for hyperoxia could explain the differences between our findings and those of Kilgannon et al. and Bellomo et al. [2, 3]. For this reason, we performed a sensitivity analysis examining the effect of varying effects of thresholds of hyperoxia on mortality (presented on the additional file 1). This found no association between a $\mathrm{PaO} 2>$ $300 \mathrm{mmHg}$ and mortality.

We agree with the authors that it is important not to miss confounding variables. Importantly, Kilgannon et al. and Bellomo et al. included patients who died within the first $24 \mathrm{~h}$ of ICU admission; these patients were excluded from our primary analysis. When they were included in a further sensitivity analysis, those with a $\mathrm{PaO} 2>300 \mathrm{mmHg}$ had a higher mortality. This was consistent with the findings of Kilgannon et al. and Bellomo et al. The median ICU length of stay for non-survivors following cardiac arrest is short, typically, $1.5-2$ days [2, 3]. Kaplan-Meier analysis demonstrates the majority of excess in mortality associated with hyperoxia occurs in the first day of ICU admission [2]. As discussed in our paper, two thirds of patients who die in the first $24 \mathrm{~h}$ have withdrawal of life sustaining therapy based on pre-existing co-morbidities or perceived poor neurological prognosis [6]. Yet, these patients have a disproportionate risk of exposure to hyperoxia [7]. This confounder may, in part, explain the association between hyperoxia with a $\mathrm{PaO} 2>300$ $\mathrm{mmHg}$ and mortality. To remove this confounder, we excluded those who died in the first $24 \mathrm{~h}$ of ICU admission. The difference in population studied in our paper may help account for the differences between our findings and previous research [2, 3].

Secondly, we agree with the authors that the mechanism of death would have further aided the interpretation of our findings. We recognize this is a limitation of our research.

Finally, while we agree that bundles of care are relevant in the management of post cardiac arrest patients [5], further research is needed to inform mandatory components of these care bundles. Our research is a step towards achieving that goal.

\section{Acknowledgements}

None.

\section{Authors' contributions}

BV and RJ wrote the manuscript. The author(s) read and approved the final manuscript.

\section{Funding}

None.

\section{Availability of data and materials}

Not applicable.

Ethics approval and consent to participate

Not applicable.

\section{Consent for publication}

Not applicable.

\section{Competing interests}

None.

Received: 8 July 2020 Accepted: 22 July 2020

Published online: 03 September 2020

\section{References}

1. McGuigan PJ, Shankar-Hari M, Harrison DA, et al. The interaction between arterial oxygenation and carbon dioxide and hospital mortality following out of hospital cardiac arrest: a cohort study. Version 2. Crit Care. 2020;24(1): 336.

2. Kilgannon J, Jones AE, Shapiro NI, et al. Association between arterial hyperoxia following resuscitation from cardiac arrest and in-hospital mortality. JAMA. 2010;303(21):2165-71 https://doi.org/10.1001/jama.2010. 707.

3. Bellomo R, Bailey M, Eastwood GM, et al. Arterial hyperoxia and in-hospital mortality after resuscitation from cardiac arrest. Crit Care. 2011;15:R90 https://doi.org/10.1186/cc10090.

4. Nolan JP, Soar J, Cariou A, et al. European Resuscitation Council and European Society of Intensive Care Medicine Guidelines for Postresuscitation Care 2015: section 5 of the European Resuscitation Council Guidelines for Resuscitation 2015. Resuscitation. 2015;95:202-22 https://doi. org/10.1016/j.resuscitation.2015.07.018.

5. Jouffroy $R$, Vivien B. Bundle of care taking into account time to improve long-term outcome after cardiac arrest. Crit Care. 2018;22(1):192. https://doi. org/10.1186/s13054-018-2128-4.

6. Elmer J, Torres C, Aufderheide TP, Austin MA, Callaway CW, Golan E, et al. Association of early withdrawal of life-sustaining therapy for perceived neurological prognosis with mortality after cardiac arrest. Resuscitation. 2016;102:127-35. https://doi.org/10.1016/j.resuscitation.2016.01.016.

7. Elmer J, Scutella M, Pullalarevu R, et al. The association between hyperoxia and patient outcomes after cardiac arrest: analysis of a high-resolution database. Intensive Care Med. 2015;41(1):49-57.

\section{Publisher's Note}

Springer Nature remains neutral with regard to jurisdictional claims in published maps and institutional affiliations. 